\title{
Protagonismo das Cooperativas na Promoção dos Objetivos de Desenvolvimento Sustentável Reflexões Teóricas e Agenda de Pesquisa
}

\author{
http://dx.doi.org/10.21527/2237-6453.2021.54.83-103
}

Recebido em: $10 / 3 / 2020$

Aceito em: 28/10/2020

\author{
Antônio João Hocayen-da-Silva ${ }^{1}$, Alessandra Hocayen da Silva²
}

\begin{abstract}
RESUMO
Buscou-se, com o presente Ensaio Teórico, refletir acerca de como as organizações cooperativas podem contribuir para a consecução dos Objetivos de Desenvolvimento Sustentável (ODS). A presente proposta torna-se essencial na medida em que busca discutir acerca desta relação, contribuindo com as discussões sobre o papel e as contribuições do cooperativismo na concretização dos ODSs e suas Metas, considerando suas especificidades em termos de organização e de gestão, bem como doutrina e filosofia cooperativistas. Partindo-se dos atributos da natureza do movimento cooperativista, e da evidente manifestação de contradições e de limites no modelo dominante e hegemônico de sociedade, as Organizações Cooperativas, por meio de seus atores sociais, guiadas por princípios coletivos de solidariedade, reciprocidade e compartilhamento, assumem papel de destaque na promoção dos ODSs, atreladas a uma proposta de bem-estar social, justiça social, qualidade de vida e transformações culturais ao redor do mundo, tornando-se determinantes no processo de conscientização, transformação e mudança cultural dos indivíduos de modo que possam repensar a ação e o papel desempenhado no mundo.
\end{abstract}

Palavras-chave: Doutrina e filosofia cooperativista. Bem-estar social. Qualidade de vida. Transformação Cultural.

\section{PROTAGONISM OF COOPERATIVES IN PROMOTING SUSTAINABLE DEVELOPMENT GOALS:} REFLECTIONS AND RESEARCH AGENDA

\begin{abstract}
The aim of this Theoretical Essay was to reflect on how cooperative organizations can contribute to the achievement of the Sustainable Development Goals (SDGs). This proposal becomes essential insofar as it seeks to demonstrate and discuss about this relationship, contributing to discussions about the role and contributions of cooperatives in achieving the SDGs and their Goals, considering their specificities in terms of organization and management, as well as, cooperative doctrine and philosophy. Starting from the attributes resulting from the nature of the cooperative movement, as well as the evident manifestation of contradictions and limits in the dominant and hegemonic model of society, the Co-operative Organizations, through their social actors, guided by collective principles of solidarity, reciprocity and sharing, assume a prominent role in promoting the SDGs in the world, linked to a proposal for social well-being, social justice, quality of life and cultural transformations around the world. They become determinants in the process of awareness, transformation and cultural change of individuals so that they can rethink the action and the role played in the world.
\end{abstract}

Keywords: Cooperative Doctrine and Philosophy. Social Welfare. Quality of Life. Cultural Transformation.

\footnotetext{
${ }^{1}$ Autor correspondente. Universidade Estadual do Centro-Oeste (Unicentro). Departamento de Administração, Campus Irati. Rua Professora Maria Roza Zanon de Almeida, Bairro Engenheiro Gutierrez, CEP 84505-677 - Irat/PR, Brasil. http://lattes.cnpq.br/9173263810446736. https://orcid.org/0000-0003-4516-1484. hocayen@yahoo.com.br

2 Universidade Federal do Mato Grosso do Sul (UFMS). Campo Grande/MS, Brasil.
} 
Em um estudo seminal, Begnis, Arend e Estivalete (2014) buscaram compreender a produção do conhecimento científico sobre cooperativas, considerando as publicações da Revista de Economia e Sociologia Rural, visando a revelar a relevância do tema. Diante dos resultados encontrados, contudo, os autores observaram que "cooperativa", "cooperativismo" e "cooperação", no período de 2002 a 2011, representou reduzido número de publicações científicas; estudos com "referências predominantemente da área de economia e versando sobre questões vinculadas ao desempenho econômico das cooperativas e seus associados" (BEGNIS; AREND; ESTIVALETE, 2014, p. 99).

Com o intuito de elucidar melhor a questão, a partir da pesquisa na base de dados do SPELL (2018a) com os termos "cooperativa", "cooperativas" e "cooperativismo", é possível encontrar como resultados, respectivamente, 315, 190 e 23 artigos. Certamente em alguns casos são apresentados como resultados artigos em comum para os três termos utilizados na consulta. A inferência que se apresenta em relação a essa busca, entretanto, diz respeito à importância e à atenção com que pesquisadores de diferentes áreas do conhecimento têm tratado o assunto no meio acadêmico-científico.

Embora seja elevado o volume de publicações na área - cerca de 500 registros - (SPELL, 2018a), destaca-se nas pesquisas encontradas o predomínio de uma multiplicidade de fenômenos sociais investigados, bem como de subtemas atrelados às cooperativas e ao cooperativismo, não sendo possível identificar um tema específico que domine o corpus das pesquisas publicadas. Assuntos que variam dos mais corriqueiros, como sobre os princípios e a educação cooperativista, até os mais atuais, como governança cooperativa e integração cooperativista. Percebe-se, ainda, a existência de estudos envolvendo temas específicos das áreas de Administração, Economia e Contabilidade aplicados à realidade de Organizações Cooperativas.

Ao consultar sobre a temática "Objetivos de Desenvolvimento Sustentável" nas publicações que compõem a base de dados SPELL (2018b), o sistema apontou a existência de uma única publicação sobre o assunto. Após pesquisa similar no Scielo (2018), foram encontrados quatro artigos em áreas correlatas à saúde. Tais resultados indicam que a discussão sobre os ODSs no contexto do cooperativismo, mesmo tendo sido definidos em 2015, ainda não se tornou objeto de estudo e investigação entre pesquisadores que se dedicam a analisar os fenômenos sociais em cooperativas.

É sabido que o dever de garantir a concretização desses objetivos é de todos, gestores públicos, empresas privadas e instituições sem fins lucrativos, bem como da sociedade como um todo. Nesse conjunto de responsáveis, as Sociedades Cooperativas, em virtude da representatividade e papel que têm desempenhado nos últimos anos (TRUGILHO et al., 2014), tornam-se fundamentais para a consecução dos propósitos definidos na Assembleia da ONU.

Assim sendo, as especificidades que caracterizam as organizações cooperativas, cujos pressupostos fundamentais estão atrelados a fatores como responsabilidade, democracia, liberdade e solidariedade (OCB, 2018), "contribuem para um futuro social e econômico mais seguro, ressaltando os valores éticos de honestidade, franqueza, responsabilidade social e cuidado com o próximo" (ANNIBELLI, 2008, p. 223).

Nesse contexto, as cooperativas podem ser entendidas como mecanismos centrais no processo de consecução dos ODSs, seja assumindo práticas e ações que levem aos mesmos, ou ainda na conscientização da população sobre a importância de mudan- 
ças de hábitos e comportamentos para que tais propósitos se tornem efetivos no prazo estabelecido, principalmente em virtude de que "o cooperativismo pode ser considerado como instrumento econômico e social, [...], haja vista seu potencial emancipatório, pois serve como instrumento de inclusão, de resgate da cidadania e, portanto, de desenvolvimento" (ANNIBELLI, 2008, p. 223).

O movimento cooperativista tem representado um modelo singular de organização que se situa muito além de retorno financeiro e crescimento no mercado. Essas organizações buscam promover a integração de forças e a colaboração de todos os integrantes de um grupo com objetivo de alcançar benefícios e melhorias nas condições de vida, trabalho e existência para seus integrantes. De acordo com Pagnussatt (2004, p. 163), "as cooperativas baseiam-se em [...] princípios contrários ao modelo econômico capitalista que prega a autoperformance e a lucratividade em todas as suas ações". Desta forma, caracterizam-se como modelos organizacionais que se alinham aos pressupostos dos ODSs em atendimento às demandas sociais, bem como, conforme discutido por Martín et al. (2020), às contradições ambientais vivenciadas pela sociedade.

As cooperativas têm como base, portanto, a reunião de pessoas que buscam condições diferenciadas e benefícios comuns, guiadas por relações de coletividade e ajuda mútua, na busca pelo crescimento e desenvolvimento coletivo (MARTINS; PASSADOR, 2009), que criam uma atmosfera singular e propícia para o surgimento de ações que visam a promover desenvolvimento, contemplando as dimensões humana, econômica, social e ambiental (BIALOSKORSKI NETO; BALIEIRO, 2000). Ike et al. (2019) destacam a escassez de pesquisas científicas que tenham como propósito central compreender as ações organizacionais direcionais para a consecução dos ODSs, contribuindo com o avanço científico do conhecimento na área. Deste modo, considerando a relevância do movimento cooperativista no Paraná, "movimentação econômica representando em torno de $15 \%$ de toda a riqueza produzida no Estado do Paraná, [...] mais de 1.247 mil cooperados, 83.267 empregados e o número de pessoas que, direta ou indiretamente dependem de suas ações supera 3,5 milhões" (OCEPAR, 2018, p. 2), e tendo em vista a incipiência de pesquisas que tenham proposto investigar os ODSs no contexto das cooperativas e a natureza do movimento cooperativista em sua concepção, propõe-se uma reflexão teórica guiada pelo seguinte questionamento: Como as organizações cooperativas podem contribuir para a consecução dos Objetivos de Desenvolvimento Sustentável - ODSs?

O presente ensaio teórico torna-se essencial à medida que se busca refletir acerca desta relação, colaborando com as discussões sobre o papel e as contribuições do cooperativismo na concretização dos ODSs e suas metas, considerando suas especificidades em termos de organização e de gestão. Para tanto, conforme enfatizado por Meneghetti (2011, p. 321), em um "ensaio a orientação é dada não pela busca das respostas e afirmações verdadeiras, mas pelas perguntas que orientam os sujeitos para as reflexões mais profundas", não considerando a pretensão de aplicações imediatas em estudos teóricos (RICHARDSON, 2017). Pesquisas teóricas não apresentam estruturas predefinidas ou procedimentos metodológicos padronizados (MENEGHETTI, 2011). Guiam-se pela pretensão de propor novos arranjos teóricos capazes de contribuir com o entendimento acerca de determinados fenômenos sociais (RICHARDSON, 2017), considerando 
que as verdades, tidas como certas, são questionadas (MENEGHETTI, 2011). Conforme afirmam Boava, Macedo e Sette (2020, p. 89), "o ensaio possibilita a libertação do pensamento, na busca pelos mistérios e mitos que povoam as mentes dos pesquisadores".

Sendo assim, o presente ensaio teórico está estruturado em seis seções, a saber: 1) Inicialmente discorre-se a introdução, em que são apresentados elementos gerais que caracterizam a presente proposta de estudo, com o problema de pesquisa e o objetivo central do estudo; 2) Em seguida estão as reflexões teóricas atreladas aos objetivos de desenvolvimento sustentável - ODS -, delimitando-se o surgimento e proposta dos mesmos; 3) Parte-se para um debate acerca do contexto social, econômico, político e ambiental de gênese dos objetivos de desenvolvimento sustentável; 4) Buscando responder à pergunta de pesquisa, tem-se uma discussão sobre a natureza das organizações cooperativas e os objetivos de desenvolvimento sustentável; 5) Finalmente, as considerações finais com uma agenda de pesquisa buscando contribuir com o avanço do conhecimento teórico sobre o tema; e 6) as referências utilizadas na construção do trabalho.

\section{EMERGÊNCIA DOS OBJETIVOS DE DESENVOLVIMENTO SUSTENTÁVEL}

Embora separados geograficamente, as nações mundiais têm vivenciado problemas e contradições similares (BURALLI et al., 2018); "Questões que direta ou indiretamente afetam a saúde e a qualidade de vida da nossa população" (BURALLI et al., 2018 , p. 1). Neste contexto, pensar a solução de uma série de problemas e conflitos vivenciados por diferentes nações ao redor do mundo, teria levado líderes mundiais a refletir coletivamente acerca de demandas sociais, econômicas, políticas e ambientais. Este movimento representa a preocupação de todos com o futuro do planeta e, consequentemente, com o futuro das próximas gerações.

O resultado deste processo foi à delimitação dos 17 Objetivos de Desenvolvimento Sustentável - ODSs -, atrelados à Agenda 2030 para o Desenvolvimento Sustentável, pela cúpula da ONU em setembro de 2015, sendo inseridos, de fato, nos debates e ações dos países a partir de janeiro de 2016 (ONU, 2018).

Diferentemente dos Objetivos de Desenvolvimento do Milênio - ODMs -, os ODSs buscam ampliar o foco de aplicação e o potencial de erradicação da pobreza no mundo (MARTín et al., 2020), exigindo de gestores públicos, nas esferas municipal, estadual e federal, em todos os países, uma postura proativa no planejamento e na aplicação de estratégias que garantam a sustentabilidade social, econômica e ambiental do planeta; medidas que promovam o alinhamento entre os propósitos de crescimento econômico e o respeito ao homem e à natureza (ONU, 2018).

Os 17 ODSs, descritos no Quadro 1, acompanhados de suas 169 metas, passaram a representar uma agenda de compromissos coletivos das nações no mundo com aspectos sociais, econômicos e ambientais determinantes para a construção de um mundo mais igualitário, pacífico e ambientalmente equilibrado; agenda que delimita diretrizes consistentes para políticas públicas de governantes nas próximas duas décadas (AÇÃOEDUCATIVA, 2018), integrando ações locais, regionais, nacionais e internacionais (MARTín et al., 2020). Estas medidas são propostas com a perspectiva de levar a humanidade a resultados capazes de gerar bem-estar, justiça social e melhores condições de vida para as populações ao redor do mundo (NAKAMURA et al., 2019), minimizando contradições vivenciadas pelas sociedades nos dias atuais, bem como solucionando problemas para futuras gerações. 


\section{Quadro 1 - Objetivos de Desenvolvimento Sustentável/ODS}

\begin{tabular}{|c|c|c|}
\hline $\mathrm{N}$. & Objetivos & Metas \\
\hline 1 & $\begin{array}{c}\text { Acabar com a pobreza em todas as suas formas, em } \\
\text { todos os lugares }\end{array}$ & $\begin{array}{c}\text { Sem Pobreza: o crescimento econômico deve ser } \\
\text { inclusivo para fornecer empregos sustentáveis e } \\
\text { promover a igualdade. }\end{array}$ \\
\hline 2 & $\begin{array}{c}\text { Acabar com a fome, alcançar a segurança alimentar } \\
\text { e melhoria da nutrição e promover a agricultura } \\
\text { sustentável }\end{array}$ & $\begin{array}{l}\text { Fome Zero: o setor de alimentos e agricultura oferece } \\
\text { soluções fundamentais para o desenvolvimento e é } \\
\text { central para a erradicação da fome e da pobreza. }\end{array}$ \\
\hline 3 & $\begin{array}{l}\text { Assegurar uma vida saudável e promover o bem- } \\
\text { estar para todos, em todas as idades }\end{array}$ & $\begin{array}{l}\text { Boa Saúde e Bem-Estar: garantir vidas saudáveis e } \\
\text { promover o bem-estar de todos em todas as idades é } \\
\text { essencial para o desenvolvimento sustentável. }\end{array}$ \\
\hline 4 & $\begin{array}{l}\text { Assegurar a educação inclusiva e equitativa } \\
\text { de qualidade e promover oportunidades de } \\
\text { aprendizagem ao longo da vida para todos }\end{array}$ & $\begin{array}{c}\text { Educação de Qualidade: a obtenção de uma educação } \\
\text { de qualidade é a base para melhorar a vida das } \\
\text { pessoas e o desenvolvimento sustentável. }\end{array}$ \\
\hline 5 & $\begin{array}{c}\text { Alcançar a igualdade de gênero e empoderar todas } \\
\text { as mulheres e meninas }\end{array}$ & $\begin{array}{l}\text { Igualdade de Gênero: a igualdade de gênero não é } \\
\text { apenas um direito humano fundamental, mas um } \\
\text { fundamento necessário para um mundo pacífico, } \\
\text { próspero e sustentável. }\end{array}$ \\
\hline 6 & $\begin{array}{l}\text { Assegurar a disponibilidade e gestão sustentável da } \\
\text { água e o saneamento para todos }\end{array}$ & $\begin{array}{l}\text { Água Limpa e Saneamento: Água limpa e acessível } \\
\text { para todos é uma parte essencial do mundo em que } \\
\text { queremos viver. }\end{array}$ \\
\hline 7 & $\begin{array}{l}\text { Assegurar a todos o acesso confiável, sustentável, } \\
\text { moderno e a preço acessível à energia }\end{array}$ & $\begin{array}{c}\text { Energia Acessível e Limpa: a energia é fundamental } \\
\text { para quase todos os grandes desafios e } \\
\text { oportunidades. }\end{array}$ \\
\hline 8 & $\begin{array}{l}\text { Promover o crescimento econômico sustentado, } \\
\text { inclusivo e sustentável, emprego pleno e produtivo } \\
\text { e trabalho decente para todos }\end{array}$ & $\begin{array}{l}\text { Trabalho Decente e Crescimento Econômico: o } \\
\text { crescimento econômico sustentável exigirá que as } \\
\text { sociedades criem condições que permitam que as } \\
\text { pessoas tenham empregos de qualidade. }\end{array}$ \\
\hline 9 & $\begin{array}{c}\text { Construir infraestruturas resilientes, promover a } \\
\text { industrialização inclusiva e sustentável e fomentar } \\
\text { a inovação }\end{array}$ & $\begin{array}{c}\text { Indústria, Inovação e Infraestrutura: investimentos } \\
\text { em infraestrutura são cruciais para alcançar o } \\
\text { desenvolvimento sustentável. }\end{array}$ \\
\hline 10 & $\begin{array}{l}\text { Reduzir a desigualdade dentro dos países e entre } \\
\text { eles }\end{array}$ & $\begin{array}{l}\text { Desigualdades Reduzidas: Para reduzir as } \\
\text { desigualdades as políticas devem ser universais em } \\
\text { princípio, prestando atenção às necessidades das } \\
\text { populações desfavorecidas e marginalizadas. }\end{array}$ \\
\hline 11 & $\begin{array}{l}\text { Tornar as cidades e os assentamentos humanos } \\
\text { inclusivos, seguros, resilientes e sustentáveis }\end{array}$ & $\begin{array}{c}\text { Cidades e Comunidades Sustentáveis: é preciso haver } \\
\text { um futuro em que as cidades ofereçam oportunidades } \\
\text { para todos, com acesso a serviços básicos, energia, } \\
\text { moradia, transporte e muito mais. }\end{array}$ \\
\hline 12 & $\begin{array}{l}\text { Assegurar padrões de produção e de consumo } \\
\text { sustentáveis }\end{array}$ & $\begin{array}{l}\text { Produção e Consumo Responsáveis: produção } \\
\text { Responsável e Consumo. }\end{array}$ \\
\hline 13 & $\begin{array}{l}\text { Tomar medidas urgentes para combater a mudança } \\
\text { do clima e os seus impactos }\end{array}$ & $\begin{array}{l}\text { Ação Climática: a mudança climática é um desafio } \\
\text { global que afeta a todos, em todos os lugares. }\end{array}$ \\
\hline 14 & $\begin{array}{c}\text { Conservar e usar sustentavelmente os oceanos, } \\
\text { os mares e os recursos marinhos para o } \\
\text { desenvolvimento sustentável }\end{array}$ & $\begin{array}{l}\text { Vida Abaixo da Água: o gerenciamento cuidadoso } \\
\text { desse recurso global essencial é uma característica } \\
\text { fundamental de um futuro sustentável. }\end{array}$ \\
\hline 15 & $\begin{array}{l}\text { Proteger, recuperar e promover o uso sustentável } \\
\text { dos ecossistemas terrestres, gerir de forma } \\
\text { sustentável as florestas, combater a desertificação, } \\
\text { deter e reverter a degradação da terra e deter a } \\
\text { perda de biodiversidade }\end{array}$ & $\begin{array}{l}\text { Vida na Terra: gerir florestas de forma sustentável, } \\
\text { combater a desertificação, travar e reverter a } \\
\text { degradação do solo, travar a perda de biodiversidade }\end{array}$ \\
\hline 16 & $\begin{array}{c}\text { Promover sociedades pacíficas e inclusivas para } \\
\text { o desenvolvimento sustentável, proporcionar o } \\
\text { acesso à justiça para todos e construir instituições } \\
\text { eficazes, responsáveis e inclusivas em todos os } \\
\text { níveis }\end{array}$ & $\begin{array}{l}\text { Paz, Justiça e Instituições Fortes: acesso à justiça } \\
\text { para todos e construção de instituições eficazes e } \\
\text { responsáveis em todos os níveis. }\end{array}$ \\
\hline 17 & $\begin{array}{c}\text { Fortalecer os meios de implementação e revitalizar } \\
\text { a parceria global para o desenvolvimento } \\
\text { sustentável }\end{array}$ & $\begin{array}{l}\text { Parcerias para os Objetivos: revitalizar a parceria } \\
\text { global para o desenvolvimento sustentável. }\end{array}$ \\
\hline
\end{tabular}

Fonte: ONU (2018). 
Os ODSs foram assim definidos com o intuito de promoção da dignidade humana e da prosperidade, salvaguardando a biofísica vital da Terra bem como os processos e os serviços ecossistêmicos (NILSSON et al., 2019). A leitura dos propósitos traçados pelos ODSs permite identificar a complexidade que envolve a efetiva consecução dos mesmos, essencialmente pela possibilidade de envolvimento e ação conjunta de todas as nações, mas, principalmente, pela necessidade de investimentos financeiros robustos, nos próximos 15 anos, de modo que sejam construídos os suportes básicos para possibilitar a consecução das metas de forma igualitária em todos os continentes (SZOMSZOR, 2019).

Neste contexto, tratados como propósitos e mecanismos de promoção social indivisíveis, a tarefa desafiadora em torno dos ODSs tende a exigir não somente um discurso inclinado ao atendimento das imposições determinadas pelas agências internacionais, ou para garantir uma imagem pública ilibada perante a opinião pública; caracteriza-se como agenda dinâmica, que emerge de uma mudança de postura dos governantes para traçar estratégias e definir mecanismos que possam contribuir para a sustentabilidade dos resultados obtidos com a realização dos objetivos traçados (COSTA, 2018; NILSSON et al., 2019).

Do mesmo modo, estruturas políticas necessitam de realinhamento para que os futuros gestores sejam capazes de compreender a importância dos ODSs, mantendo e intensificando uma atuação política capaz de atender aos propósitos compartilhados pelas populações (COSTA, 2018). Nesse sentido, os desafios em torno dos ODSs apontam para a promoção de uma governança pública que atenda, de forma responsável, as demandas sociais, econômicas e ambientais importantes para o planeta. Nakamura et al. (2019) reforçam que a aplicação eficiente e consciente de recursos, bem como o conhecimento atrelado a significativas pesquisas e inovações, representaria a base para a constituição de grupos e instituições capazes de efetivar as ações traçadas pelos objetivos.

Finalmente, é importante discutir, ainda na atmosfera dos ODSs, os procedimentos de acompanhamento e avaliação (COSTA, 2018) dos resultados obtidos com as ações definidas e as mudanças conduzidas pelos atores sociais envolvidos na execução; critérios de verificação que permitam aos responsáveis refletir acerca da efetividade de suas contribuições, repensando as medidas adotadas bem como o papel das instituições públicas neste processo.

Estabelecer critérios, mecanismos, papéis e responsáveis, assim como prazos e recursos necessários, torna-se desafio central na promoção dos ODSs. Nakamura et al. (2019) e Szomszor (2019) defendem, para isso, a importância da ciência na definição de ações que possam contribuir efetivamente para a solução das contradições sociais, econômicas e ambientais vigentes nos dias atuais no mundo; incoerências que acompanharam o desenvolvimento da sociedade, ocasionando, pelas dimensões atingidas, condições precárias de vida para grande parcela da população mundial.

\section{CONTEXTO DE GÊNESE DOS OBJETIVOS DE DESENVOLVIMENTO SUSTENTÁVEL}

A sociedade para a qual foram estabelecidos os ODSs é resultado de um processo histórico de transformações sociais, políticas, ambientais e econômicas. Hobsbawm (1977) estabelece que a modernização da sociedade impulsionou a saída do homem 
do meio rural para o meio urbano. Até então inserido em um contexto de produção e criação para o autosustento, o homem passou a exercer atividades padronizadas para a produção industrial, organizada pelos detentores de capital.

Assim, a transposição do meio rural para o meio urbano, dominado por atividades industriais em massa, baseadas na exploração da mão de obra assalariada, deu início a uma lógica de mercado. Sob o ponto de vista da percepção capitalista, tal processo garantiu a constituição do mercado para o fornecimento de mão de obra necessária às atividades industriais e ao mercado de consumo para as mercadorias decorrentes do processo produtivo (BRAVERMAN, 1981; HARVEY, 2007).

Percebe-se, assim, uma reestruturação social em que as práticas coletivas e solidárias de produção, troca e compartilhamento, essenciais na configuração da vida humana associada, foram substituídas pela ação instrumental; dinâmica que assume não só as práticas sociais no contexto das organizações, mas invade o cotidiano de vida das pessoas, conduzindo as relações a partir de princípios mercadológicos (GUERREIRO RAMOS, 1989). Na Sociedade de Mercado o significado da ação social predominante esteve atrelado ao cálculo utilitário de consequências, em que o indivíduo age em razão de resultados predominantemente econômicos, cujo ganho financeiro individual, independente dos impactos ocasionados por suas ações, torna-se a orientação do comportamento humano.

Polanyi (2000) e Santos (2010) enfatizam que as transformações proporcionadas pelas promessas de progresso não se concretizam para a maioria da população, e agravam-se com a rendição dos agentes públicos aos propósitos privados individualistas das organizações. Vislumbra-se, assim, com as mesmas características dos cercamentos de terras livres, a ação utilitarista do capital na condução de uma apropriação dos mecanismos do Estado. Estes são vistos como instrumentos de promoção social da população mais carente, que passa a servir aos interesses do capital, subvertendo-se à lógica dominante da Sociedade de Mercado.

Desse modo, o agravamento da polarização entre centro e periferia pode ser percebido com a rendição do poder público aos pressupostos do sistema capitalista. Instituições governamentais, cuja função seria de prover à população condições adequadas de vida, passam a atuar alinhadas aos interesses individuais das corporações. Demandas sociais são colocadas em segundo plano por não contribuírem com a consecução desses propósitos. Acentua-se a inversão de valores com a atuação do Estado, chocando-se com seus princípios balizadores e promovendo uma minoria capaz em detrimento de uma maioria limitada; mecanismo delimitado por Santos (2010) como um processo político de cima para baixo, que desconsidera os interesses e demandas da população, substituindo o coletivo pelo individual.

Apoiando-se, porém, nas reflexões de Polanyi (2000), não se nega que a mudança seja algo inevitável para uma sociedade; o que se discute é o papel das instituições governamentais nesse processo de transformação, que, muitas vezes, acaba por promover o cerceamento dos direitos dos indivíduos com menor poder aquisitivo em razão de não serem personagens ativos na condução das mudanças, relegados a coadjuvante de um sistema social cujo domínio tende a ser de grupos isolados. 
Em decorrência das transformações da sociedade, a crença de que o próspero crescimento econômico sustentaria os pressupostos de um desenvolvimento irrestrito, em termos de regiões ou indivíduos, gerando prosperidade coletiva, demonstrou-se limitada. Por conta desta dificuldade, este processo vem sendo paulatinamente questionado à medida que se expande e se salientam contradições de ordem social, econômica, política, cultural e ambiental (SACHS, 1998).

\section{Limites e Contradições do Modelo Desenvolvimentista de Crescimento}

O modelo desenvolvimentista, propagado pelo processo de modernização da sociedade e iniciado pelo sistema capitalista de produção, não foi capaz de garantir a prosperidade prometida. Resultou, na verdade, conforme discutido por Esteva e Prakash (1998) e Santos (2010), em uma série de problemas e conflitos vivenciados por pessoas que foram relegadas a um contexto periférico de vida. Conforme destacado por Sachs (1997, p. 214) "a história nos pregou uma peça cruel"; peça no sentido de representar uma falácia, com resultados negativos incomensuráveis, como Sachs (1997, p. 216) afirma: "o mundo foi engolido por profunda crise social, agravada pela dilaceração ambiental”.

O processo de colapso social teve o homem como ator principal no papel de defesa e promoção do modelo desenvolvimentista de crescimento, seja como personagem dominante, detentor de capital, ou no grupo dominado, vivenciando a experiência de trabalhadores explorados e excluídos social e economicamente (SACHS, 1997).

A busca pelo crescimento e a promoção do progresso econômico, acabaram por desestruturar o bem-estar das diferentes comunidades, acentuando as injustiças sociais. O modo de vida, baseado no saber tradicional, transmitido ao longo dos anos, foi substituído por um comportamento individualista e puramente utilitarista dos indivíduos (POLANYI, 2000); progresso entendido enquanto engrenagem de dominação do ser e de sua consciência, reforçando os elos de alienação da maioria da sociedade em detrimento dos detentores de capital (ADORNO; HORKHEIMER, 1985).

Hobsbawm (1988) enfatiza que com o processo da industrialização o mundo foi dividido em dois polos: as regiões que experimentaram o surto de crescimento, desenvolvimento e prosperidade, principalmente financeira; e territórios periféricos, posicionados às margens dos centros comerciais. As regiões periféricas, cada vez mais comuns no mundo, tornavam-se ainda "palco" dos reflexos negativos das propostas capitalistas. Grande parte da população, nesses contextos, via-se limitada em termos de saúde, educação, alimentação, moradia, saneamento básico e lazer. Embora uma parcela estivesse diretamente ligada a essa Sociedade de Mercado, por desempenhar o papel de operário no processo, percebe-se que a alguns não era possibilitado, nem mesmo, pôr em prática as mazelas do consumismo.

De modo complementar, Hobsbawm (1996) destaca que, embora seu discurso enfatize a possibilidade de progresso a toda a humanidade, reservando aos indivíduos uma prosperidade antes nunca experimentada, os pressupostos do sistema capitalista conduziram a sociedade para um processo de dominação. "A maior parte da população mundial tornou-se vítima daqueles cuja superioridade econômica, tecnológica e consequentemente militar era inconteste e parecia indestrutível" (HOBSBAWM, 1996, p. 171). 
Além de não cumprir as promessas de prosperidade, as quais têm defendido ao longo dos anos, as práticas econômicas individualistas, assumidas pela Sociedade de Mercado a partir de meados do século 20, têm enfrentado dificuldades para criar empregos a todos os indivíduos que precisam trabalhar (GUERREIRO RAMOS, 1989). Guerreiro Ramos (1989, p. 13) afirma que "[...] o desenvolvimento das forças produtoras, se tornou à lógica da vida humana em geral. Mesmo a subjetividade privada do indivíduo caiu prisioneira da racionalidade instrumental". As desigualdades nos espaços periféricos tornam-se mais agudas em virtude da apreensão e controle de informações, por aqueles atores sociais dominantes, tendo em vista seus interesses escusos, alheios aos anseios da coletividade.

Considerando-se as disfuncionalidades percebidas, conforme apontam Vizeu, Meneghetti e Seifert (2012, p. 575), "o sistema de produção capitalista se reproduz explorando os indivíduos, destruindo as condições naturais e eliminando as possibilidades de que as relações humanas sejam de fato a centralidade do processo civilizatório". 0 domínio de informação por um grupo reduzido de pessoas ou empresas determina que "a periferia do sistema capitalista acaba se tornando ainda mais periférica, seja porque não dispõe totalmente dos novos meios de produção, seja porque lhe escapa a possibilidade de controle" (SANTOS, 2010, p. 39).

O uso indiscriminado de recursos da natureza, na percepção de pesquisadores e de membros da sociedade em geral, normalmente excluídos, apresentou-se como uma das principais falácias do desenvolvimento. Na tentativa de reafirmação de suas bases, contudo, atores sociais, imersos na crença das potencialidades dos pressupostos do desenvolvimento, adotam as premissas acerca do pensamento ecológico com o intuito de instituir as ideias de "desenvolvimento sustentável" como instrumento para justificar e reafirmar o próprio desenvolvimento (ESTEVA; PRAKASH, 1998).

A crença de que progresso e desenvolvimento proporcionariam prosperidade a todos, institucionalizada e legitimada por um discurso ideológico do sistema capitalista, construiu uma Sociedade de Mercado ancorada em uma estrutura de consumo "onde as massas enormes de pessoas são induzidas a acreditar que desejam (e, portanto, devem comprar) aquilo de que não precisam" (GUERREIRO RAMOS, 1989, p. 91).

Conforme afirmam Adorno e Horkheimer (1985, p. 104), "o progresso separa literalmente as pessoas", sendo responsável pela confecção de uma série de instrumentos e práticas que promoveram o enfraquecimento das relações sociais, distanciando as pessoas e, desse modo, massificando a alienação social; sistema que, a partir dos mecanismos de comunicação, tornam produtos e serviços atraentes aos olhos dos consumidores, de modo que consomem sem qualquer possibilidade de questionamento ou reflexão acerca da real necessidade daquilo que estão adquirindo.

Sendo assim, a inversão de valores na sociedade, que teve substituída sua lógica de compartilhamento coletivo para um excessivo comportamento individualista, base da sociedade de mercado, resultou em um contexto mitigado por conflitos sociais, econômicos e ambientais (ESTEVA; PRAKASH, 1998), responsáveis pela devastação da vida humana associada, impondo significativo colapso à dignidade da civilização. 
Finalmente, Santos (2010) destaca que o abandono de princípios de solidariedade acabou seccionando a convivência entre os homens e a responsabilidade de cada um para com os demais. Esteva e Prakash (1998) assinalaram que os próprios limites determinantes das propostas de desenvolvimento e de crescimento, atrelados aos mecanismos de industrialização do capital, tornaram-se mola propulsora de debates e reflexões acerca de mecanismos capazes de reconstruir ou reconquistar uma sociedade mais igualitária, com melhores condições de vida, hoje e amanhã; movimento em que pessoas, instituições públicas e organizações privadas tornam-se atores centrais de uma prática crítico-reflexiva.

\section{NATUREZA DAS COOPERATIVAS E OS OBJETIVOS DE DESENVOLVIMENTO SUSTENTÁVEL - ODSS}

O surgimento do movimento cooperativista no mundo coincide historicamente com uma acentuada manifestação de contradições do sistema capitalista de produção (BENECKE, 1980; BENEVIDES PINHO, 1982; SANTOS, 2004; ALTMAN, 2009). Em 1844, com a gênese da primeira cooperativa no mundo, um grupo de operários, indignado com as más situações vivenciadas no cotidiano de trabalho e as péssimas condições de sobrevivência de inúmeras famílias dos grandes centros urbanos, deixa claro, para os detentores de capital e os gestores públicos, que mudanças eram necessárias para reduzir os impactos gerados pela massificação da produção e do consumo (NORONHA et al., 1976; BENEVIDES PINHO, 1982; ABRANTES, 2004).

A base deste movimento de indignação e insurgência dentro de um contexto dominado por práticas hegemônicas de organização e gestão da produção, que invadia ainda o comportamento das pessoas em seu contexto social, foi o princípio da solidariedade (BENEVIDES PINHO, 1982). Buscavam seus precursores se posicionarem contrários aos ditames de individualismo propostos pelos industriais, que aumentavam suas riquezas e representação social em virtude da exploração dos trabalhadores e da marginalização dos menos favorecidos na sociedade (NORONHA et al., 1976).

A união dos operários em torno de um novo modelo de organização, que tem como pressuposto o sujeito coletivo, seja no contexto de trabalho ou no contexto social, como essência da ação, manifesta-se como um movimento de defesa dos interesses sociais e ambientais da população. A gênese das cooperativas alinha-se aos debates e reflexões de cientistas políticos e sociais da época, que já se debruçavam no questionamento, na compreensão e na proposta de soluções para as contradições decorrentes da sociedade de mercado (BENECKE, 1980; BENEVIDES PINHO, 1982).

Princípios como igualdade, solidariedade e reciprocidade, fundamentais nas discussões em torno da perspectiva de uma racionalidade substantiva, passam a ser evidenciados pelo discurso de promotores do movimento cooperativista, com o intuito de levar as pessoas à ressignificação de suas percepções ideológicas e de suas práticas sociais, afastando-as dos princípios de uma racionalidade instrumental, fundamento do contexto capitalista (BENECKE, 1980). Por meio da ajuda mútua e da cooperação, permite-se resgatar na sociedade a primazia dos valores humanos em detrimento dos postulados monetários (RATNER, 2009). 
Nesse sentido, tendo como natureza a cooperação, o movimento cooperativista busca dirimir não somente as questões sociais, econômicas e ambientais de seus participantes diretos, mas possibilitar que os resultados advindos de suas ações sejam percebidos por toda a humanidade (BENECKE, 1980; ABRANTES, 2004). A intenção dos precursores pode ser entendida como uma tentativa de, por meio do trabalho e da renda equitativos, contribuir com a construção de uma sociedade mais justa e equilibrada em termos sociais e ambientais; uma sociedade em que sejam reduzidas as contradições percebidas na época; uma sociedade em que fosse mitigada, conforme enfatizado por Santos (2010), a polarização entre centro e periferia.

Assim, buscando concretizar seus propósitos e fortalecer a difusão do movimento nas arestas da sociedade, seus idealizadores promulgaram suas ideias nos Princípios Cooperativistas (NORONHA et al., 1976; BENEVIDES PINHO, 1982; ABRANTES, 2004); elementos que passaram a dar significado aos postulados do cooperativismo, assumindo o papel de carro-chefe das organizações cooperativas ao redor do mundo; princípios que teriam sido pensados a partir do contexto geral da sociedade e se caracterizam conforme mostra o Quadro 2.

\section{Quadro 2 - Princípios Cooperativistas.}

\begin{tabular}{|c|c|}
\hline Princípios & Descritores \\
\hline $\begin{array}{l}\text { 1. Adesão } \\
\text { Voluntária e Livre }\end{array}$ & $\begin{array}{l}\text { Cooperativas são abertas para todas as pessoas que queiram participar, que } \\
\text { estejam alinhadas ao seu objetivo econômico e dispostas a assumir suas } \\
\text { responsabilidades como membro. Não existe nenhuma discriminação por sexo, } \\
\text { raça, classe, crença ou ideologia. }\end{array}$ \\
\hline $\begin{array}{l}\text { 2. Gestão } \\
\text { Democrática }\end{array}$ & $\begin{array}{l}\text { Cooperativas são organizações democráticas controladas por todos os membros } \\
\text { que participam ativamente na formulação de suas políticas e nas tomadas de } \\
\text { decisão, e os representantes oficiais são eleitos por todo o grupo. }\end{array}$ \\
\hline $\begin{array}{l}\text { 3. Participação } \\
\text { Econômica dos } \\
\text { Membros }\end{array}$ & $\begin{array}{l}\text { Em uma cooperativa os membros contribuem equitativamente para o capital } \\
\text { da organização. Parte do montante é, normalmente, propriedade comum da } \\
\text { cooperativa e os membros recebem remuneração limitada ao capital integralizado, } \\
\text { quando há. Os excedentes da cooperativa podem ser destinados às seguintes } \\
\text { finalidades: benefícios aos membros, apoio a outras atividades aprovadas pelos } \\
\text { cooperados ou para o desenvolvimento da própria cooperativa. Tudo sempre } \\
\text { decidido democraticamente. }\end{array}$ \\
\hline $\begin{array}{l}\text { 4. Autonomia e } \\
\text { Independência }\end{array}$ & $\begin{array}{l}\text { As cooperativas são organizações autônomas, de ajuda mútua, controladas por } \\
\text { seus membros, e nada deve mudar isso. Se uma cooperativa firmar acordos com } \\
\text { outras organizações, públicas ou privadas, deve fazer em condições de assegurar o } \\
\text { controle democrático pelos membros e a sua autonomia. }\end{array}$ \\
\hline $\begin{array}{l}\text { 5. Educação, } \\
\text { Formação e } \\
\text { Informação }\end{array}$ & $\begin{array}{l}\text { Ser cooperativista é se comprometer com o futuro dos cooperados, do movimento } \\
\text { e das comunidades. As cooperativas promovem a educação e a formação para } \\
\text { que seus membros e trabalhadores possam contribuir para o desenvolvimento } \\
\text { dos negócios e, consequentemente, dos lugares onde estão presentes. Além } \\
\text { disso, oferece informações para o público em geral, especialmente jovens, sobre a } \\
\text { natureza e vantagens do cooperativismo. }\end{array}$ \\
\hline 6. Intercooperação & $\begin{array}{l}\text { Cooperativismo é trabalhar em conjunto. É assim, atuando juntas, que as } \\
\text { cooperativas dão mais força ao movimento e servem de forma mais eficaz aos } \\
\text { cooperados. Seja unidas em estruturas locais, regionais, nacionais ou até mesmo } \\
\text { internacionais, o objetivo é sempre se juntar em torno de um bem comum. }\end{array}$ \\
\hline $\begin{array}{l}\text { 7. Interesse pela } \\
\text { Comunidade }\end{array}$ & $\begin{array}{l}\text { Contribuir para o desenvolvimento sustentável das comunidades é algo natural ao } \\
\text { cooperativismo. As cooperativas fazem isso por meio de políticas aprovadas pelos } \\
\text { membros. }\end{array}$ \\
\hline
\end{tabular}

Fonte: OCB (2019). 
Segundo a descrição, os princípios cooperativistas representam os pressupostos do movimento (NORONHA et al., 1976; ABRANTES, 2004), concebidos a partir de interesses coletivos de grupos marginalizados no contexto da sociedade de mercado, com o intuito de solucionar as contradições e injustiças sociais (BENECKE, 1980) evidentes em um sistema que tem como base o individualismo, a produção em massa, o consumismo exacerbado, a exploração de mão de obra, o uso indiscriminado da natureza e a reprodução do capital que se encontra nas mãos de pequenas parcelas da sociedade.

É comum na definição dos descritores dos princípios cooperativistas categorias teóricas como cooperação, transformação e equilíbrio nas dimensões social, econômica e ambiental. A perspectiva da cooperação se traduz na promoção da ação coletiva que busca atender aos interesses comuns dos membros da cooperativa; ação que envolve não só a prática cotidiana, mas também as decisões conjuntas que valorizam a essência do ser humano no cotidiano do cooperativismo (RATNER, 2009; FLECHA; CRUZ, 2011).

Ao promover o resgate de valores humanos atrelados a uma dimensão social coletiva, portanto, os resultados percebidos traduzem-se em significativo potencial de mudanças em quatro significativas dimensões: social, ecológica, saúde e paz; transformações que se iniciam no seio da organização cooperativa e reverberam para a comunidade em seu entorno e, ao ganhar potencial, geram benefícios para a vida das pessoas em todo o mundo (RATNER, 2009).

Nesse processo, o que garante a harmonia entre os interesses individuais e as necessidades coletivas diz respeito ao fundamento do equilíbrio. As cooperativas atuam em defesa do respeito aos valores humanos e aos limites impostos pela natureza, e equilibram os pressupostos de produção e consumo consciente, de crescimento e decrescimento, de uso consciente dos recursos naturais e do econômico condicionado ao social; dicotomias que traduzem a ação em movimento de promoção de bem-estar social e condições adequadas de sobrevivência a todos, assumindo assim, papel central no processo de emancipação dos marginalizados na sociedade (BHOWMIK; SARKER, 2002).

Assim, atribui-se uma interpretação do movimento cooperativista, a partir de uma perspectiva sociopolítica e ideológica, que delimita sua natureza não econômica (BENECKE, 1980) que tem revelado o potencial de contribuição de tais organizações para a consecução dos propósitos estabelecidos pelos Objetivos de Desenvolvimento Sustentável - ODSs. Essas expectativas, segundo Benecke (1980, p. 111), podem ser traçadas em dois eixos centrais integrados: “i) espera-se que as cooperativas mudem o comportamento econômico e social da população; e ii) devido à mudança de atitude, as cooperativas consigam impulsionar maior eficiência a nível macroeconômico e social". Tais atributos representam princípios históricos do movimento cooperativista capazes de atender aos pressupostos apontados por Ike et al. (2019) como essenciais para a promoção dos ODSs, mecanismos, políticas e programas de educação, além de instituições fortes, sejam públicas, privadas ou não governamentais.

Benecke (1980) apontou ainda que a educação, alinhada aos pressupostos cooperativistas, representa um caminho possível, assumido por organizações não governamentais, governos e empresas privadas, guiados por um comportamento substantivo para uma mudança de atitude da sociedade, visando a reduzir as diferenças e os conflitos percebidos com a polarização social, massificada pelas atitudes individualistas de desenvolvimento econômico e de crescimento organizacional. 
Três benefícios são convergentes em um contexto de promoção de uma educação atrelada aos postulados da doutrina e filosofia cooperativistas, conforme destacado por Benecke (1980, p. 112): “i) Educação para o incremento do nível cultural geral; ii) Educação da população para a solidariedade; e iii) Educação para fortalecimento da consciência democrática".

A educação, ancorada por princípios, valores e virtudes cooperativistas, contribui para o resgate das populações marginalizadas que são alijadas de contexto social e econômico em virtude da democratização de conhecimentos e informações que levam ao empoderamento do indivíduo de forma que seja capaz de construir uma consciência crítico-reflexiva, pensando em seu cotidiano e em seu contexto social. O sujeito pavimenta, assim, relações sociais instituídas de solidariedade e destituídas de um pensamento individualista de ambição, capazes de gerar mudanças na estrutura social das diferentes nações do mundo a ponto de minimizar os problemas atuais enfrentados pela sociedade (BENECKE, 1980).

Embora as Organizações Cooperativas tenham sido relegadas à invisibilidade durante os movimentos de reflexão e delimitação dos ODS, por ocasião do preconceito e da crença de que o contexto de referência do movimento cooperativa está delimitado pelas práticas sociais locais, não sendo capazes de atribuir resultados nas dimensões nacionais e internacionais (ACl; OIT, 2019), a natureza coletiva e solidária das Organizações Cooperativas desmonta tais argumentos e atribui-lhes papel preponderante no processo de discussão e de promoção dos ODSs no mundo (GOUVEIA, 2016).

Principalmente, pelo fato de as Organizações Cooperativas conduzirem suas ações práticas atreladas a uma doutrina e a uma filosofia que prezam pelo equilíbrio social-econômico e ambiental, respeitando valores humanos compartilhados socialmente (ACl; OIT, 2019). A capacidade múltipla de representação e de ação das cooperativas pode ser reforçada ainda pela atuação em 13 diferentes ramos da economia, a saber: i) Agropecuário; ii) Consumo; iii) Crédito; iv) Infraestrutura; v) Habitacional; vi) Saúde; vii) Trabalho, Produção de Bens e Serviços; viii) Educacional; ix) Especial; $x$ ) Mineral; xi) Produção; xii) Turismo e Lazer; e xiii) Transporte (OCB, 2019), o que significa mundialmente um importante instrumento de transformação social não somente para os associados, mas, também, para os diferentes enclaves sociais em que as cooperativas estão inseridas.

O montante de 13 ramos, com todas as suas cooperativas centrais e singulares, bem como os cooperados e funcionários em diferentes regiões do país, formam um leque de práticas cotidianas que, guiadas por princípios de solidariedade, ajuda mútua e pressupostos de união de pessoas para um objetivo comum, instituem-se como mola propulsora dos ODSs na sociedade. Certos cuidados, contudo, devem ser tomados para a não adoção e generalização do discurso de competências das organizações cooperativas, uma vez que, de forma genérica, os 17 ODSs possuem relevante aderência aos propósitos de ação das cooperativas. É essencial garantir a sustentabilidade das ações em torno dos ODSs, buscando o papel das cooperativas a partir do desmembramento desses objetivos em suas respectivas metas e indicadores (GOUVEIA, 2016).

Torna-se essencial, portanto, o reconhecimento de que em alguns eixos temáticos dos ODSs as cooperativas possuem aderência direta, como: i) assegurar a educação inclusiva e equitativa de qualidade e promover oportunidades de aprendizagem ao longo 
da vida para todos; ii) alcançar a igualdade de gênero e empoderar todas as mulheres e meninas; iii) promover o crescimento econômico sustentado, inclusivo e sustentável, emprego pleno e produtivo e trabalho decente para todos; iv) construir infraestruturas resilientes, promover a industrialização inclusiva e sustentável e fomentar a inovação; v) assegurar padrões de produção e de consumo sustentáveis; vi) tomar medidas urgentes para combater a mudança do clima e os seus impactos; e vii) proteger, recuperar e promover o uso sustentável dos ecossistemas terrestres, gerir de forma sustentável as florestas, combater a desertificação, deter e reverter a degradação da terra e deter a perda de biodiversidade.

Nos demais, o posicionamento se faz de forma indireta, a saber: i) acabar com a pobreza em todas as suas formas, em todos os lugares; ii) acabar com a fome, alcançar a segurança alimentar e melhoria da nutrição e promover a agricultura sustentável; iii) assegurar uma vida saudável e promover o bem-estar para todos, em todas as idades; iv) assegurar a disponibilidade e gestão sustentável da água e o saneamento para todos; v) assegurar a todos o acesso confiável, sustentável, moderno e a preço acessível à energia; vi) reduzir a desigualdade dentro dos países e entre eles; vii) tornar as cidades e os assentamentos humanos inclusivos, seguros, resilientes e sustentáveis; viii) conservar e usar sustentavelmente os oceanos, os mares e os recursos marinhos para o desenvolvimento sustentável; ix) promover sociedades pacíficas e inclusivas para o desenvolvimento sustentável, proporcionar o acesso à justiça para todos e construir instituições eficazes, responsáveis e inclusivas em todos os níveis; e x) fortalecer os meios de efetivação e revitalizar a parceria global para o desenvolvimento sustentável.

Esta divisão em dois eixos, aderência direta e indireta, não pode ser entendida como um atendimento parcial dos ODSs. Reconhecidamente as organizações cooperativas, considerando as múltiplas atividades desenvolvidas, bem como os diferentes setores da economia em que estão inseridas, possuem competência para contribuir de forma significativa com a consecução dos ODSs propostos pela ONU; aderência que se fortalece com ações conjuntas entre atores organizacionais capazes de abandonar os pressupostos de competição e assumir a cooperação como princípio essencial para a promoção de um mundo mais harmônico.

Ações conjuntas, contudo, tornam-se essenciais. Considerando-se a complexidade em torno dos ODSs, Ike et al. (2019) destaca que as organizações no setor privado podem sentir dificuldades de atendimento e efetivação em todos os eixos. É essencial, nesse contexto, a união de esforços com outras instituições, empresas e governos para potencializar os possíveis resultados e garantir que sejam atendidos os objetivos traçados. Possibilita-se, assim, a expansão das propostas de cooperação para além dos contornos cooperativistas, fomentando o estabelecimento de redes e relacionamentos interorganizacionais entre atores institucionais, públicos ou privados, inclinados à promoção de atitudes e comportamentos atrelados aos ODSs. Parcerias para além da intercooperação, já comum no contexto das organizações cooperativas, contribuiriam com a instituição de um movimento coletivo de conscientização de representantes da sociedade capazes de garantir que a consecução dos ODSs seja sustentável e que seus resultados sejam percebidos no longo prazo. Como destacado por Rendtorff (2019), há articulação mediada pelo fortalecimento das parcerias entre público e privado. 
Neste contexto, Gouveia (2016) discute possíveis mecanismos estratégicos a partir dos quais as cooperativas podem direcionar suas ações e, assim, fomentar aquelas plataformas assumidas como prioritárias no contexto dos ODSs. Para tanto, deve haver o compartilhamento de experiências entre as cooperativas singulares, centrais ou federações e as confederações, e entre as cooperativas e empresas privadas e instituições governamentais, para que as informações possam tornar mais eficientes os mecanismos utilizados. Divulgando os resultados de sucessos obtidos, as cooperativas podem, ainda, atrair a atenção de novos parceiros bem como reforçar o comprometimento dos envolvidos.

Destaca-se, também, o papel do cooperativismo no contexto político, colaborando na definição de políticas públicas alinhadas aos propósitos dos ODSs, atuando no convencimento dos gestores públicos acerca da importância de medidas e ações que estejam condicionadas aos propósitos coletivistas e solidários, e lutando pelos interesses e necessidades de grupos menos favorecidos ou marginalizados na sociedade; atuação que deve ter por base a construção de alianças estratégicas em diferentes níveis e contextos para promover a ajuda mútua em uma dimensão institucional (GOUVEIA, 2016). Nesse sentido, os atores participantes das redes e dos relacionamentos interorganizacionais teriam seus propósitos estratégicos internos bem como uma agenda estratégica conjunta.

Desse modo, visando a fomentar a ação das cooperativas na consecução dos ODSs, foram delimitadas quatro plataformas de ação instituídas como norte central das organizações cooperativas no mundo pelos próximos anos até a agenda de 2030 . Ficaram assim estabelecidas: i) melhoria e acesso a bens e serviços essenciais para toda a população; ii) erradicação da pobreza em todos os sentidos e contextos sociais; iii) proteção ao ambiente e à biodiversidade dominante na natureza; e iv) construção de um sistema alimentar mais saudável, acessível e sólido (ACl, 2019).

Finalmente, a $\mathrm{ACl}$ (2019) traça uma discussão em torno de recomendações essenciais que lançariam luz sob o potencial de contribuição do movimento cooperativista para a concretização dos propósitos estabelecidos pelos ODSs, conforme Quadro 3.

Quadro 3 - Recomendações para aproximação entre as cooperativas e os ODSs

\begin{tabular}{|c|c|}
\hline Recomendação & Descrição \\
\hline $\begin{array}{l}\text { Reconhecimento } \\
\text { Internacional }\end{array}$ & $\begin{array}{l}\text { As Nações Unidas deveriam reconhecer o papel das cooperativas } \\
\text { na realização do desenvolvimento sustentável, incluindo-as nos } \\
\text { indicadores, metas e mecanismos de financiamento para os Objetivos de } \\
\text { Desenvolvimento Sustentável. }\end{array}$ \\
\hline $\begin{array}{c}\text { Proatividade das } \\
\text { Organizações Cooperativas }\end{array}$ & $\begin{array}{l}\text { Cooperativas devem ser proativas e intervir nos debates sobre a } \\
\text { agenda para o desenvolvimento depois de } 2015 \text { para todos os níveis } \\
\text { (local, nacional, regional e internacional) para garantir a possibilidade } \\
\text { de compartilhar suas experiências em alcançar o desenvolvimento } \\
\text { sustentável. }\end{array}$ \\
\hline $\begin{array}{l}\text { Representação e Defesa do } \\
\text { Sistema Cooperativista }\end{array}$ & $\begin{array}{l}\text { Organizações de cooperativas, nacionais, regionais e internacionais } \\
\text { devem melhorar suas funções de representação e defesa do setor, } \\
\text { para obter maior presença e reconhecimento do ponto de vista das } \\
\text { cooperativas na agenda para o desenvolvimento depois de } 2015 \text { e nos } \\
\text { debates políticos internacionais em geral. }\end{array}$ \\
\hline
\end{tabular}

Fonte: $\mathrm{ACl}$ (2019, p. 17). 
As recomendações evidenciadas no Quadro 3 têm como propósito reforçar a importância da natureza do cooperativismo ao redor do mundo; natureza regida por pressupostos de ajuda mútua, autogestão, respeito aos valores humanos, uso consciente de recursos naturais e cooperação, bem como por valores de solidariedade, responsabilidade, democracia e igualdade.

Esses elementos configuram uma identidade única para as cooperativas e alinham-se aos propósitos que deram origem aos ODSs na ONU, uma vez que visa a garantir a autonomia e a emancipação das pessoas e a proteção da natureza, tornando o mundo um ambiente melhor e mais receptivo para as futuras gerações. É um espaço capaz de promover o equilíbrio entre as dimensões social, econômica e ambiental, essenciais para a promoção de princípios de sustentabilidade em diferentes contextos e distintas relações humanas.

\section{CONSIDERAÇÕES FINAIS}

A partir de um ensaio teórico fundamentado na natureza das organizações cooperativas e nos elementos caracterizadores dos Objetivos de Desenvolvimento Sustentável - ODSs -, sem a pretensão de esgotar as possibilidades científicas em torno do assunto, mas, sim, convocar ao debate acadêmico, o presente estudo assumiu como questão balizadora de debate a seguinte pergunta: Como as organizações cooperativas podem contribuir para a consecução dos Objetivos de Desenvolvimento Sustentável - ODS? Guiou-se por uma perspectiva de que ao mundo é atribuído um conjunto de contradições que tem, de forma significativa, invadido diferentes enclaves sociais e implicado transformações nas relações humanas.

Na pré-história a ação coletiva já se manifestava como essencial para a sobrevivência das famílias e das comunidades, tendo em vista as dificuldades encontradas na natureza quando da necessidade de proteção e alimentação. Posteriormente, a cooperação é reforçada pela união de povos ao redor do mundo em virtude de guerras e invasões de seus territórios, ou, ainda, para a expansão de seus domínios para atender ao crescimento populacional. Por fim, a cooperação ganha contornos de valores humanos, e, no contexto do movimento capitalista de dominação, cresce com grupos que teriam sido excluídos e mantidos à margem da sociedade de mercado.

As cooperativas surgiram na atmosfera de ações coletivas com a atribuição de potencializar melhores condições de vida e de trabalho para famílias que se encontram em situações de vulnerabilidade e marginalizadas em decorrência da ascensão e consolidação do sistema de produção dominante e hegemônico em diferentes épocas e contextos sociais; sistema cuja ação é determinada pelo padrão de comportamento dos indivíduos atrelados às suas atividades.

Concomitantemente, nos dias atuais, em torno de um discurso de união e defesa de interesses comuns, foram proclamados os Objetivos de Desenvolvimento Sustentável - ODSs -, com a atribuição de melhorar a qualidade de vida das pessoas e proteger a biodiversidade no planeta. A consecução dos ODSs, de modo que seus resultados sejam percebidos por todas as nações, requer a união de pessoas, governos, instituições não governamentais e empresas privadas. É importante reconhecer os "ODS como um instrumento para o desenvolvimento econômico e a regeneração, contribuindo para o empoderamento econômico e mudança social e política" (RENDTORFF, 2019, p. 511). 
Nesse sentido, epistemologicamente o movimento de construção e instituição dos ODSs, seus propósitos e suas metas, institui uma configuração de mundo distinta das percepções decorrentes do sistema capitalista de produção, que, até então, a partir de um discurso de geração e distribuição de riquezas e conquistas, determinava sua supremacia como a única forma capaz de organizar a sociedade e dar significado aos diferentes papéis sociais vigentes.

Naturalmente expõe-se o reconhecimento da existência de contradições na sociedade, que tem como fator gerador a instrumentalidade predominante na forma de organização social instituída pela gênese do sistema capitalista de produção. Pressupostos, portanto, de desenvolvimento, crescimento e prosperidade tornam-se flagelos de um modo de vida cujos resultados acentuaram a dicotomia entre centro e periferia.

A instituição de dois polos no mundo agravou a marginalização dos atores sociais, destituídos de bem de capital em decorrência da valorização daqueles que, economicamente ativos, tornam-se engrenagem de reprodução do sistema. Tal marginalização culminaria na efervescência de problemas sociais, econômicos e ambientais que levaram ao questionamento da validade e das reais contribuições do modelo econômico hegemônico e dominante. Coloca-se, assim, em suspeição, a partir de um movimento coletivo de reflexão crítica, a veracidade dos pilares que sustentam sua reprodução.

Dessa forma, as prioridades estabelecidas pelos ODSs e suas metas demandam dos diferentes atores sociais uma mudança de atitude e não somente a instituição de medidas e $o$ atendimento de exigências sociais, econômicas e ambientais. Espera-se que as transformações possibilitem modificações nos princípios e valores que condicionam a percepção e a ação humana em um contexto de compartilhamento social; contexto em que, à guisa de referência do comportamento humano, seja dominado por uma atribuição do coletivo em detrimento do individual.

Finalmente, considerando os atributos decorrentes da natureza do movimento cooperativista, bem como a evidente manifestação de contradições do modelo dominante e hegemônico de sociedade, as cooperativas, por meio de seus atores sociais, assumem papel de destaque na promoção dos ODSs no mundo. Tornam-se determinantes tanto na definição de ações e estratégias de curto, médio e longo prazos, que possam contribuir com a geração de benefícios sociais, econômicos e políticos tanto para a população quanto para um processo de conscientização, transformação e mudança cultural dos indivíduos, de modo que possam repensar a ação e o papel desempenhado no mundo.

Reforçando o movimento já instituído por Begnis, Arend e Estivalete (2014) acerca da necessidade de avanço nas pesquisas sobre cooperativas, cooperativismo e cooperação, para consolidação do campo no Brasil, ao final das reflexões teóricas promovidas com o presente ensaio são instituídas as propostas para futuras pesquisas. Em razão da incipiência do tema no contexto acadêmico, são reduzidas as pesquisas que se dedicam a compreender as nuances que envolvem as organizações cooperativas e os ODSs. Mesmo assim, torna-se importante a reflexão científica em virtude de contribuir com o entendimento acerca dos pressupostos, da forma de organização e gestão, bem como das possíveis implicações e ainda das limitações em torno da promoção dos ODSs. Visando a contribuir com esse movimento científico, são propostos, a seguir, alguns encaminhamentos que podem levar ao amadurecimento do conhecimento no campo de estudos: 
- compreender o contexto histórico de gênese dos Objetivos de Desenvolvimento Sustentável - ODS -, levando ao entendimento dos princípios e dos valores defendidos por seus idealizadores, bem como as contradições do sistema dominante que deram significado ao movimento de reflexão crítica dos líderes mundiais. Estudar a história desse processo permite identificar o potencial de alinhamento da doutrina e filosofia cooperativistas, atreladas aos pressupostos de uma política de baixo para cima, como discutido por Santos (2010), com o arcabouço de metas elencadas pelos ODSs;

- estabelecer parâmetros e indicadores para análise e avaliação da divulgação dos ODSs na sociedade, avaliando a percepção das pessoas e organizações acerca do potencial de transformação e solução dos problemas sociais, econômicos e ambientais dos ODSs, bem como o papel das cooperativas nessa dinâmica, e, ainda, dos resultados obtidos com as ações iniciais conduzidas pelos países envolvidos; critérios que podem auxiliar no ajuste de medidas e comportamentos no contexto de promoção dos ODSs, permitindo também o compartilhamento de experiências que tragam uma maior efetividade dos mesmos;

- verificar as possíveis implicações do movimento de intercooperação no contexto do sistema cooperativista para a efetiva realização dos ODSs; analisando a efetividade do alinhamento entre cooperativas centrais e individuais no processo de planejamento de ações futuras que possam garantir o equilíbrio entre o crescimento econômico e o desenvolvimento sustentável;

- mapear os relacionamentos e as parcerias instituídas com o propósito de consolidação dos ODSs, avaliando o papel dos atores participantes; a troca e o compartilhamento de recursos, conhecimentos e competências; os ganhos e benefícios, individuais e coletivos, decorrentes da ação em rede; bem como o papel da governança na gestão dos propósitos e dos mecanismos de instituição de estratégias e de aplicação de recursos em nível de relacionamentos interorganizacionais, buscando garantir a sustentabilidade dos resultados obtidos; e

- estudar as dificuldades e as barreiras enfrentadas pelos idealizadores para a divulgação, o desenvolvimento e a consolidação dos ODSs, na sociedade, de modo que os gestores públicos, as instituições não governamentais e as empresas privadas possam se posicionar e buscar soluções para garantir a concretização dos propósitos estabelecidos. O entendimento acerca dos fatores limitadores pode auxiliar no esclarecimento da relação entre os ODSs e os fatores culturais de uma sociedade, bem como as contribuições do movimento cooperativista na intermediação, aproximação e aderência entre ambos.

\section{AGRADECIMENTOS}

Agradecemos o apoio financeiro do Conselho Nacional de Desenvolvimento Científico e Tecnológico - CNPq -, por meio da Chamada CNPq/Sescoop № 07/2018. 


\section{REFERÊNCIAS}

ABRANTES, J. Associativismo e cooperativismo: como a união de pequenos empreendedores pode gerar emprego e renda no Brasil. Rio de Janeiro: Interciência, 2004.

AÇÃOEDUCATIVA. A implementação dos Objetivos de Desenvolvimento Sustentável no Brasil e os desafios das metas em educação. Disponível em: http://www.acaoeducativa.org.br/desenvolvimento/. Acesso em: 20 mar. 2018.

ACI. Alianza Cooperativa Internacional. Las cooperativas y los Objetivos de Desarrollo Sostenible: Debate sobre el desarrollo después de 2015. Disponível em: https://www.ica.coop/es/llamado-recogida-fondos-serie-iniciativas-cooperativas-ods. Acesso em: 10 abr. 2019.

ACI. Alianza Cooperativa Internacional; OIT. Organización Internacional del Trabajo. Las cooperativas y los Objetivos de Desarrollo Sostenible: Debate sobre el desarrollo después de 2015. Disponível em: https://www.ilo.org/wcmsp5/groups/public/---ed_emp/---emp_ent/---coop/documents/publication/ wcms_307228.pdf. Acesso em: 10 abr. 2019.

ADORNO, T.; HORKHEIMER, M. Dialética do esclarecimento: fragmentos filosóficos. Rio de Janeiro: Zahar, 1985.

ALTMAN, M. History and Theories of Cooperatives. International Encyclopedia of Civil Society, Springer Science+Business Media, LLC, 2009.

ANNIBELLI, M. B. A ordem econômica brasileiro e o cooperativismo. Revista Eletrônica do CEJUR, Curitiba, PR, a. 2, v. 1, n. 3, ago./dez. 2008.

BEGNIS, H. S. M.; AREND, S. C.; ESTIVALETE, V. F. B. Em frente ao espelho: a produção do conhecimento em cooperativas na Revista de Economia e Sociologia Rural. RESR, Piracicaba, SP, v. 52, n. 1, p. 99-116, jan./mar. 2014, - impressa em maio 2014.

BENECKE, D. W. Cooperação e desenvolvimento: o papel das cooperativas no processo do desenvolvimento econômico nos países do terceiro mundo. Porto Alegre; Recife: Coojornal Assocene, 1980.

BENEVIDES PINHO, D. Manual do cooperativismo: pensamento cooperativo e o cooperativismo brasileiro. São Paulo: CNPq, 1982.

BHOWMIK, S.; SARKER, K. Worker cooperatives as alternative productions systems. Work and Occupations, 29, p. 460-482, 2002.

BIALOSKORSKI NETO, S.; BALIEIRO, C. F. Capital social e cooperativas na agricultura do Estado de São Paulo: um ensaio analítico. Texto para Discussão. Ribeirão Preto: Comissão de Pesquisa e Publicações da FEA-RP/USP, 2000.

BOAVA, D. L. T.; MACEDO, F. M. F.; SETTE, R. S. Contribuições do ensaio teórico para os estudos organizacionais. Revista Administração em Diálogo, v. 22, n. 2, p. 69-90, maio/jun./jul./ago. 2020.

BRAVERMAN, H. Gerência científica. In: BRAVERMAN, H. Trabalho e capital monopolista. Rio de Janeiro: Zahar, 1981.

BURALLI, R. J.; CANELAS, T.; CARVALHO, L. M.; DUIM, E.; ITAGYBA, R. F.; FONSECA, M. OLIVER, S. L.; CLEMENTE, N. S. Moving towards the Sustainable Development Goals: the UNLEASH Innovation Lab experience. Ambiente \& Sociedade, São Paulo, v. 21, p. 1-20, 2018.

COSTA, M. A. Como avaliar o alcance dos Objetivos de Desenvolvimento Sustentável? Desafios e possibilidades para a agenda global de avaliação. Revista Brasileira de Políticas Públicas e Internacionais, v. 3, n. 1, p. 100-123, jun. 2018.

ESTEVA, G.; PRAKASH, M. S. Beyond development, what? Development in Practice, v. 8, n. 3, Aug. 1998.

FLECHA, R.; CRUZ, I. S. Cooperation for Economic Success: The Mondragon Case. Analyse \& Kritik, Stuttgart: Lucius \& Lucius, 1, p. 157-170. 2011.

GOUVEIA, R. As cooperativas e os Objetivos de Desenvolvimento Sustentável. Documentos de Discusión. CUMBRE COOPERATIVA DE LAS AMÉRICAS. "COOPERATIVAS: ASOCIATIVIDAD PARA EL DESARROLLO SOSTENIBLE" 4., de 14 a 18 de noviembre de 2016, Montevideo-Uruguay. Disponível em: https://www. aciamericas.coop/squelettes/ivcumbre/documentos/Eje3_RodrigoGouveia.pdf. Acesso em: 25 abr. 2018. GUERREIRO RAMOS, A. A nova ciência das organizações: uma reconceituação da riqueza das nações. Rio de Janeiro: FGV, 1989.

HARVEY, D. Condição pós-moderna: uma pesquisa sobre as origens da mudança cultural. São Paulo: Loyola, 2007.

HOBSBAWM, E. J. A era das revoluções: Europa 1789-1848. Rio de Janeiro: Paz e Terra, 1977.

HOBSBAWM, E. J. A era do capital: 1848-1875. Rio de Janeiro: Paz e Terra, 1996.

HOBSBAWM, E. J. A era dos impérios: 1875-1914. Rio de Janeiro: Paz e Terra, 1988. 
IKE, M.; DONOVAN, J. D.; TOPPLE, C.; MASLI, E. K. The process of selecting and prioritising corporate sustainability issues: Insights for achieving the Sustainable Development Goals. Journal of Cleaner Production, 236, 2019.

MARTÍN, E. G.; GIORDANO, R.; PAGANO, A.; KEUR, P. V. D.; COSTA, M. M. Using a system thinking approach to assess the contribution of nature based solutions to sustainable development goals. Science of the Total Environment, 738, 2020.

MARTINS, M. M.; PASSADOR, C. Z. O papel da organização cooperativa no desenvolvimento de uma região: um estudo de caso de uma cooperativa de pequenos produtores de São Paulo. CONGRESSO DA SOCIEDADE BRASILEIRA DE ECONOMIA, ADMINISTRAÇÃO E SOCIOLOGIA RURAL, SOBER, 47., 2009, Porto Alegre. Anais [...]. Porto Alegre, 2009.

MENEGHETTI, F. K. O que é um ensaio-teórico? Rev. Adm. Contemp., [on-line]. 2011, v. 15, n. 2, p. 320-332. Disponível em: http://www.scielo.br/scielo.php?script=sci_arttext\&pid=S1415-65552011000200010\&Ing= pt\&nrm=iso. Acesso em: 10 mar. 2019.

NAKAMURA, M.; PENDLEBURY, D.; SCHNELL, J.; SZOMSZOR, M. Navigating the Structure of Research on Sustainable Development Goals. Publicado em: abr. 2019. Disponível em: https://clarivate.com/wp-content/uploads/dlm_uploads/2019/03/Navigating-the-Structure-of-Research-on-Sustainable-Development-Goals.pdf. Acesso em: 10 maio 2019.

NILSSON, M.; GRIGGS, D.; VISBECK, M.; RINGLER, C.; MCCOLLUM, D. Introduction a Framework For Understanding Sustainable Development Goal Interactions. Disponível em: https://council.science/ cms/2017/03/SDGs-interactions-framework.pdf. Acesso em: 10 mar. 2019.

NORONhA, A. V.; TAVARES, A. B.; KUgelMAS, A. L.; MOTTA, D. T. Cooperativismo. São Paulo: Cupolo, 1976.

OCB. Organização das Cooperativas Brasileiras. O que é o cooperativismo? Disponível em: www.ocb.org. br. Acesso em: 25 ago. 2018.

OCB. Organização das Cooperativas Brasileiras. Princípios cooperativistas. Disponível em: www.ocb.org. br. Acesso em: 10 maio 2019.

OCEPAR. Organização das Cooperativas do Paraná. Cooperativismo paranaense: desenvolvimento sustentável no campo e na cidade. Disponível em: http://www.paranacooperativo.coop.br/ppc/. Acesso em: 20 mar. 2018.

ONU. Organização das Nações Unidas. Sustainable Development Goals. Disponível em: https://sustainabledevelopment.un.org/sdgs. Acesso em: 25 maio 2018.

PAGNUSSATT, A. Guia do cooperativismo de crédito: organização, governança e políticas corporativas. Parto Alegre: Editora Sagra Luzatto, 2004.

POLANYI, K. A grande transformação: as origens da nossa época. Rio de Janeiro: Campus, 2000.

RATNER, C. Cooperativism: A Social, Economic, and Political Alternative to Capitalism. Capitalism Nature Socialism, 20:2, p. 44-73, 2009.

RENDTORFF, J. D. Sustainable Development Goals and progressive business models for economic transformation. Local Economy, v. 34(6), p. 510-524, 2019.

RICHARDSON, R. J. Pesquisa social: métodos e técnicas. São Paulo: Atlas, 2017.

SACHS, I. Desenvolvimento numa economia mundial liberalizada e globalizante: um desafio impossível? Estudos Avançados, São Paulo, v. 11, n. 30, 1997.

SACHS, I. O desenvolvimento enquanto apropriação dos direitos humanos. Estudos Avançados, São Paulo, v. 12, n. 33, 1998.

SANTOS, B. S. Produzir para viver. Os caminhos da produção não capitalista. Porto: Edições Afrontamento, 2004.

SANTOS, M. Por uma outra globalização: do pensamento único à consciência universal. Rio de Janeiro: Record, 2010.

SCIELO. Objetivos de desenvolvimento sustentável. Disponível em: http://www.scielo.br/cgi-bin/wxis.exe/ iah/. Acesso em: 23 mar. 2018.

SPELL. Cooperativa, cooperativas e cooperativismo. Disponível em: http://www.spell.org.br/documentos/ resultadobusca/?eou\%5B\%5D=\&tipo_busca=simples\&campo\%5B\%5D=TITULO\&texto\%5B\%5D=cooperativismo\&eou\%5B\%5D=E\&campo\%5B\%5D=TITULO\&texto\%5B\%5D=\&eou\%5B\%5D=E\&campo\%5B\%5D=TITULO\&texto\%5B\%5D=\&mes_inicio=\&ano_inicio=\&mes_fim=\&ano_fim=. Acesso em: 23 mar. 2018 a. 
SPELL. Objetivos de desenvolvimento sustentável. Disponível em: http://www.spell.org.br/documentos/ resultadobusca/?eou\%5B\%5D=\&tipo_busca=simples\&campo\%5B\%5D=TITULO\&texto\%5B\%5D=Objetivos+de+Desenvolvimento+Sustent\%C3\%A1vel+(ODS)\&eou\%5B\%5D=E\&campo\%5B\%5D=TITULO\&texto $\% 5 B \% 5 \mathrm{D}=\&$ eou $\% 5 \mathrm{~B} \% 5 \mathrm{D}=\mathrm{E} \&$ campo\%5B\%5D=TITULO\&texto\%5B\%5D=\&mes_inicio=\&ano_inicio=\&mes_fim=\&ano_fim $=$. Acesso em: 23 mar. 2018b.

SZOMSZOR, M. Navigating the Structure of Research on Sustainable Development Goals. Institute for Scientific Information. Publicado em: 10 maio 2019. Disponível em: https://clarivate.com/g/sustainable-development-goals. Acesso em 25 maio 2019.

TRUGILHO, S. W.; NASCIMENTO, A. P. S.; OlIMPIO, G. A.; RODRIGUES, J. A.; SILVA, L. C. G. Evolução e perspectivas do cooperativismo no Brasil. ENCONTRO LATINO AMERICANO DE INICIAÇÃO CIENTÍFICA, 18., ENCONTRO LATINO AMERICANO DE PÓS-GRADUAÇÃO, 14., ENCONTRO DE INICIAÇÃO À DOCÊNCIA, 4., 2014, São José dos Campos. Anais [...]. São José dos Campos: Universidade do Vale do Paraíba, 2014.

VIZEU, F.; MENEGHETTI, F. K.; SEIFERT, R. E. Por uma crítica ao conceito de desenvolvimento sustentável. Cadernos EBAPE.BR (FGV), São Paulo, v. 10, p. 6, 2012. 